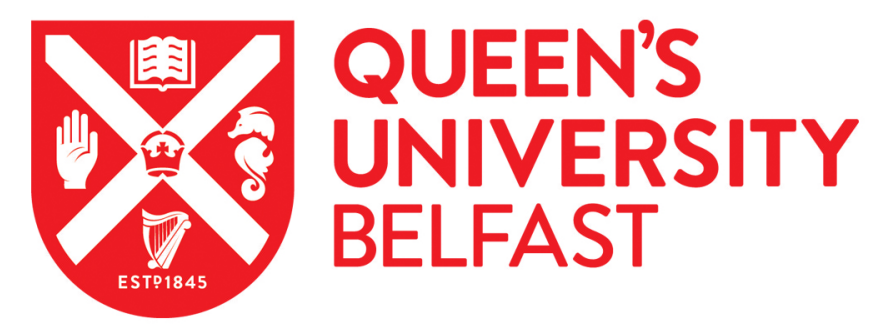

\title{
Insight of the interface of electroless Ni-P/SiC composite coating on aluminium alloy, LM24
}

Franco, M., Sha, W., Tan, V., \& Malinov, S. (2015). Insight of the interface of electroless Ni-P/SiC composite coating on aluminium alloy, LM24. Materials and Design, 85, 248-255.

https://doi.org/10.1016/j.matdes.2015.06.159

Published in:

Materials and Design

Document Version:

Peer reviewed version

Queen's University Belfast - Research Portal:

Link to publication record in Queen's University Belfast Research Portal

Publisher rights

(c) 2015, Elsevier. Licensed under the Creative Commons Attribution-NonCommercial-NoDerivatives 4.0 International

$\mathrm{http}: / /$ creativecommons. org/licenses/by-nc-nd/4.0/which permits distribution and reproduction for non-commercial purposes, provided the author and source are cited.

\section{General rights}

Copyright for the publications made accessible via the Queen's University Belfast Research Portal is retained by the author(s) and / or other copyright owners and it is a condition of accessing these publications that users recognise and abide by the legal requirements associated with these rights.

Take down policy

The Research Portal is Queen's institutional repository that provides access to Queen's research output. Every effort has been made to ensure that content in the Research Portal does not infringe any person's rights, or applicable UK laws. If you discover content in the Research Portal that you believe breaches copyright or violates any law, please contact openaccess@qub.ac.uk. 
Insight of the interface of electroless $\mathrm{Ni}-\mathrm{P} / \mathrm{SiC}$ composite coating on aluminium alloy, LM24

M. Franco ${ }^{1}$, W. Sha ${ }^{1, *}$, V. Tan ${ }^{1}$, S. Malinov ${ }^{2}$

${ }^{1}$ School of Planning, Architecture and Civil Engineering, Queen's University Belfast, Belfast BT7 1NN, UK

${ }^{2}$ School of Mechanical and Aerospace Engineering, Queen's University Belfast, Belfast BT7 1NN, UK

* Corresponding author. Tel.: +44 28 90974017; fax: +44 2890974278.

E-mail address: w.sha@qub.ac.uk (W. Sha). 


\begin{abstract}
Electroless nickel composite coatings with silicon carbide, $\mathrm{SiC}$, as reinforcing particles deposited with Ni-P onto aluminium alloy, LM24, having zincating as under layer were subjected to heat treatment using air furnace. The changes at the interface were investigated using scanning electron microscope (SEM) and energy dispersive X-ray (EDX) to probe the chemistry changes upon heat treatment. Microhardness tester with various loads using both Knoop and Vickers indenters was used to study the load effect clubbed with the influence of second phase particles on the coating at the vicinity of the interface. It was observed that zinc was absent at the interface after elevated temperature heat treatment at $400-500{ }^{\circ} \mathrm{C}$. Precipitation of copper and nickel with a distinct demarcation (copper rich belt) along the coating interface was seen with irregular thickness of the order of $1 \mu \mathrm{m}$. Migration of copper from the bulk aluminium alloy could have been the factor. Brittleness of the coating was confirmed on heat treatment when indented with Vickers. However, in composite coating the propagation of the micro crack was stopped by the embedded particles but the micro cracks continue in the matrix when not interrupted by second phase particles $(\mathrm{SiC})$.
\end{abstract}

Keywords: coating materials; metal matrix composites; surface and interfaces; diffusion; microstructure; scanning electron microscope, SEM 


\section{Introduction}

Surface modification is desirable for inferior material that lacks target properties when selecting for a particular application requiring a level of surface performance. Aluminium alloys are such type that needs surface modification for engineering applications in automobile and aerospace domains (especially surfaces prone to exposure and contact degradation) despite having other beneficial properties like good strength-to-weight ratio, excellent thermal and electrical conductivity [1]. Metal coatings by electrochemical techniques are promising and widely used owing to their economy and better output. The deposition of nickel with phosphorus [2] reinforced with hard particles like silicon carbide, $\mathrm{SiC}$, using electroless method is a versatile composite coating that can transform the inferior $\mathrm{Al}$ alloy substrate $[3,4]$. Other types of particles like $\mathrm{Al}_{2} \mathrm{O}_{3}[5]$ and $\mathrm{CeO}_{2}[6]$ have also been used in nickel based coatings.

Aluminium alloys are not easy for metal deposition because of the quick formation of oxide film when exposed to air or even during rinsing that can lead to adhesion failure [7]. It is worthless having satisfactory surface properties post coating without having good adhesion. Common pre-treatment process is zincating in which a thin film of zinc $(10-40 \mathrm{~nm})$ [8] is deposited prior to the plating. Zincating is the result of the electrochemical exchange reaction between zinc ions in the solution and the aluminium metal to deposit zinc crystallites at the expense of aluminium dissolution (etching) [9-13]. Several investigators developed and studied the zincating film and its distribution. Jin et al. [11] studied the zincating process by employing ultrasonic technique which produces dense population of small $\mathrm{Zn}$ particles and increases the coverage of $\mathrm{Zn}$ intermediate layer. Sufficient nucleation of dense population of small $\mathrm{Zn}$ particles is required for the good adhesion of nickel deposit. Valova et al. [12] observed that the presence of chemical inactive alloying elements like $\mathrm{Si}$ and $\mathrm{Mg}$ can interrupt the zincating continuity which could be unfavourable for the local adherence of the 
electroless nickel film. A small amount of electrochemically active element like $\mathrm{Cu}$ in the substrate considerably improves uniformity and density of $\mathrm{Zn}$ deposits in which $\mathrm{Cu}$ atom facilitates efficient electron transfer and subsequent nucleation of $\mathrm{Zn}$ deposition on the substrate. The electrochemically active minor element helps to affect the surface modification to favour zincating process. The thinner the zinc film the better is the performance of the adhesion [13].

For electroless nickel coating, heat treatment changes the microstructure and improves its properties such as microhardness and wear behaviour. The ideal temperature for heat treatment is $400{ }^{\circ} \mathrm{C}$ [14]. However, under this influence of high temperature there could be several microscopic changes at the interface between the substrate and the coating. For instance, the changes at vicinity of the interface could be from the thermal expansioncontraction of the dissimilar materials, closeness of melting point of zinc in zincating layer to the heat treatment temperature, hopping of atoms to another lattice site assisted by thermal effect etc. These aspects have not been found elsewhere and there is lack of information and literature on the study at the interface between this electroless coating and the aluminium substrate under the influence of heat treatment.

Thus the present work is aimed to investigate the changes along the boundary between electroless nickel coating $(\mathrm{Ni}-\mathrm{P} / \mathrm{SiC})$ and the $\mathrm{Al}$ substrate. The purpose of the work is to understand the interface of the composite coating subjected to heat treatment. The study will attempt to discuss the zincating on the particular alloy used, elemental migration and migratory aptitude and also the micro mechanical changes under loading conditions using both Knoop and Vickers from indentation perspective.

\section{Experimental details}


Three types of specimens were prepared out of aluminium alloy, LM24, as base substrate (Al-8\%Si-3.5\%Cu alloy). Specimen 1 was coated with Ni-P without zincating, specimen 2 was coated with Ni-P with zincating and specimen 3 was coated with composite $\mathrm{Ni}-\mathrm{P} / \mathrm{SiC}$ using electroless techniques. All the specimens underwent pre-treatment for cleaning prior to the coating. The cleaning process and parameters were referred from Franco et al. [3] shown in Table 1. Extreme care was taken to transfer the specimens to the in-lined cleaning solutions as quickly as possible. For composite coating, abrasive silicon carbide (size 1-7 $\mu \mathrm{m}$ ) particles were used. Prior to the plating, the particles were introduced to the bath (proprietary medium phosphorus electroless nickel base solution, NiKlad ELV 808MX, MacDermid) and stirred using magnetic stirrer for $30 \mathrm{~min}$ for homogenous suspension. Plating process and parameters are given in Table 2 [3]. Stirring rate was chosen after several trials to minimise sedimentation at the bottom and to obtain optimal distribution of the particles (stirring speed at level 5 in the magnetic stirrer, model HB502, Bibby Sterilin Ltd., UK make). In addition to it, sample rotator was used rotating the sample gently against the circular flow of the liquid in order to maximise the contact of the suspended particles with the metal piece. For adjusting the $\mathrm{pH} \sim 50 \%$ ammonium hydroxide (upward) and 10\% sulphuric acid (downward) were used.

The samples were heat treated at $300{ }^{\circ} \mathrm{C}, 400{ }^{\circ} \mathrm{C}$ and $500{ }^{\circ} \mathrm{C}$ held for 1 hour in the heating furnace at atmospheric condition. Subsequently the specimens were taken out immediately and cooled down to room temperature rapidly. The temperature range was chosen because the ideal heat treatment temperature is $400{ }^{\circ} \mathrm{C}$. It is worthwhile investigating the interface within this range and interestingly zinc melting point is close to this. Cross section samples were prepared metallographically which involved hot moulding using carbon based resin (conductive) followed by grinding and polishing using alumina solution. 
For investigating the mechanical changes at the interface under different loads using Knoop and Vickers indenter tip, microhardness tester (LECO, M-40) was employed. Loads of $25 \mathrm{gf}$, $50 \mathrm{gf}, 100 \mathrm{gf}$ and $500 \mathrm{gf}$ were applied at the interface of the coating and the substrate for without zincating and with zincating electroless nickel samples. The testing was attempted to examine any detachment of the coating at the interface under the influence of varied load conditions. Also, the effect of heat treatment and particles inclusion on the microscopic changes at the vicinity of the coating interface was investigated by employing the same tester.

The samples were observed in Nikon Eclipse ME600D optical microscope for preliminary checking of the polished samples and indent marks after the impression of Knoop and Vickers indenters. The more elaborate details of the microscopic changes around the indent notch were further examined using FE-SEM (QUANTA FEG250) equipped with OXFORD X-Act. Energy dispersive X-ray (EDX) run by Aztec version 2.0 software was used for chemical composition analysis. The diameter and depth resolution of EDX analysis of the samples depends on the density of the material. It is calculated to be about $0.8 \mu \mathrm{m}$ diameter and $1 \mu \mathrm{m}$ depth for nickel surface considering $8.9 \mathrm{~g} / \mathrm{cm}^{3}$ as density and for aluminium alloy, LM24 surface having density of $2.79 \mathrm{~g} / \mathrm{cm}^{3}$ the diameter and depth are $2 \mu \mathrm{m}$ and $3 \mu \mathrm{m}$ respectively.

\section{Results and discussion}

Electroless nickel composite coating (Ni-P/SiC) characteristics such as phase composition, microstructure and properties like microhardness, surface roughness and wear characteristics have been reported and discussed in our previous studies $[3,4]$. In the present investigation, the zincating layer at the interface and any changes arising at the vicinity of the interface are analysed systematically. 
The zincating on flat aluminium substrate conducted prior to electroless coating is shown in Fig. 1. The surface composition, that is a mixture of the zinc layer and the underneath aluminium alloy substrate, is given in Table 3. The micrograph (Fig. 1b) shows good distribution and coverage of zinc onto aluminium substrate. The uniform distribution of fine (sub-micron sizes) zinc crystallite is beneficial to render good adhesion for plating. The finer the zinc deposit the better is the adhesion of the further coating [13]. The grooves and scratches on aluminium substrate in Fig. 1a are due to abrasive action while preparing sample. For zincating, during its process, nucleation of zinc initiates at the expense of dissolution of aluminium substrate by displacement that is accelerated by the action of sodium hydroxide present in the solution. The aluminium substrate, LM24, alloyed with silicon as major element is less active as compared to pure aluminium as such. For pure aluminium, more dissolution of aluminium and rapid nucleation of zinc and thereby dense deposition of zinc was expected and the same was observed on the immersed part of pure aluminium wire (jig) used for hanging the specimen. Whereas for LM24 alloy, owing to the presence of electrochemically inactive element $\mathrm{Si}$, less dissolution of aluminium and slow nucleation of zinc results in thin zinc layer (preliminary visual inspection). The inclusion of other electrochemically active alloying element like copper might have compensated the nonhomogenous micro excavation of aluminium by the action of sodium hydroxide, thus assisting to prevent localised micro etching around silicon. This could be the reason for the uniform distribution of the zinc crystallite on the aluminium surface. Valova et al. [12] concluded that the presence of alloying elements like silicon and magnesium can interrupt the continuity of zincating which could be unfavourable for the local adherence of the electroless nickel film. However, inclusion of electrochemically active minor element like copper enhances electron transfer and consequently increases the efficiency of nucleation of zinc deposit [13]. 
The micrographs of the cross section of the samples are shown in Figs. 2-4 to represent clearly the location of the selected points for EDX and to give morphology of the coating, interface and the substrate area. The cross section of the as deposited sample for specimen 2 is shown in Fig. 2. EDX analysis results of elements by point analysis transverse the interface on both the sides of the coating and the substrate are included in Table 3. The locations of points for EDX are chosen selectively for clear representation. Spectrum 16 from the point located on coating area shows nickel and phosphorus as expected. On approaching towards the interface detection of zinc is shown in the spectrum alongside reduction of weight percentage of nickel (from $91.6 \pm 0.4$ to $7.0 \pm 0.3$ wt. \%). Aluminium which is from the substrate is found at the vicinity of the interface and increases on going towards the substrate side. Presence of silicon in higher weight percentage might be due to the electron beam point hitting directly on the alloying element. Other alloying trace elements like $\mathrm{Cu}, \mathrm{Fe}$ and $\mathrm{Mn}$ and $\mathrm{Ni}$ (coating) from surrounding effect are also detected. Since the zincating layer is very thin, low weight (1.8 $\pm 0.2 \mathrm{wt} . \%)$ of zinc is obtained which is quite reasonable. Other elements are contributing from the base aluminium alloy substrate not from the zinc layer because zincating solution contains only zinc oxide and sodium hydroxide.

Similarly, for as-deposited composite specimen 3, weight percentage of nickel element keeps decreasing on going towards interface and aluminium weight content increases on selecting the points towards substrate side (Table 3). The detection of zinc towards the substrate side rather than exactly on the interface could be due to the substrate effect as LM24 alloy is cast one and the surface is rough and also has some pits after slicing off during sample preparation. So, zinc might have deposited onto the valley which could be underneath the cross-section surface and within the EDX detection depth range downward. Another reason might be the imperfect levelling of the mould. However, during sample moulding (metallography) extreme care was taken. If it was the imperfect flatness then the spectrum 
with points at interface would have shown more of coating composition with nickel and phosphorus having higher content of nickel. So, imperfect flatness of the mounting resin could be ruled out. Hence zinc must have deposited onto the valley and pits of the aluminium substrate. Very low zinc content is shown in the spectrum due to the deposition of thin layer (shown in the table). Detection of significant oxygen percentage could be due to contamination of natural oxide formed on the freshly exposed aluminium during cross section preparation by grinding and polishing.

For composite specimen 3 heat treated at $300{ }^{\circ} \mathrm{C}$, zinc is detected at the interface as shown in Table 3. As seen in the previous observations, nickel and phosphorus are seen in the spectrum taken from coating side and when the location is selected towards substrate side, aluminium is predominant. However, the detection of zinc in the substrate side could be due to the deposition on valley as discussed earlier. Presence of zinc at this heat treatment condition could indicate the stability of the zinc crystallite that still remains as the intermediate layer between the substrate and the composite coating but zinc could also be in solid solution of Al after diffusion at $300{ }^{\circ} \mathrm{C}$. On further heat treatment at $400{ }^{\circ} \mathrm{C}$ (Fig. 3), the detection of zinc at the interface is shifted further at lower side towards the substrate (Table 3). On selecting another location (S8) absence of zinc is obtained. There could be chances of diffusion or migration as the temperature is close to melting point of zinc. In addition, significant copper percentage shows up at the interface. Hence on elevated temperature heat treatment zinc at the interface which is from the zincating layer is found to be below the detection limit of EDX which could be attributed to the diffusion elsewhere since its melting point is close to the ideal heat treatment temperature of the electroless Ni-P/SiC coating.

\subsection{Diffusion of copper}


Fig. 4 shows the cross-section of the Ni-P coating heat treated at $500{ }^{\circ} \mathrm{C}$. A distinct layer is formed rich in copper having thickness about $1 \mu \mathrm{m}$. The belt is seen all along the interface with irregular thickness. The morphology looks slightly dried and charred as compared to the lower temperature heat treatment samples. This is due to the low melting temperature of aluminium substrate $\left(650\right.$ to $\left.760^{\circ} \mathrm{C}\right)[15]$ and the heat treatment temperature is close to the melting temperature. The elemental spectrum of the prominent interface shows clearly the significant weight percentage of copper found in the region (Table 3). At this elevated temperature, copper which is present in the bulk substrate could have migrated or diffused through the substrate. Confirmation of the affinity of copper migration is an interesting direction taking into account the phase diagrams of both $\mathrm{Cu}-\mathrm{Al}$ [16] and $\mathrm{Cu}-\mathrm{Ni}$ [17]. In $\mathrm{Cu}-\mathrm{Al}$ system, the solubility of $\mathrm{Cu}$ in $\mathrm{Al}$ is not high as in $\mathrm{Cu}-\mathrm{Ni}$ system. When compared with $\mathrm{Ni}, \mathrm{Al}$ is not as similar as $\mathrm{Cu}$ owing to the property differences such as atomic sizes, electronegativity, valence electrons etc.

$\mathrm{Cu}-\mathrm{Ni}$ phase diagram indicates that each component is soluble in the other and is homogenous in composition. The compatibility between these two atoms in the crystal stacking of atoms is due to the similarities in properties. The close similarities on the aspects of atomic radii, electro negativities and valences attribute to the formation of same FCC (face-centred cubic) structure when they both crystallize. Hence, analysing both the systems and in competition of migratory direction either towards $\mathrm{Ni}$ or remaining in the aluminium substrate under the influence of elevated temperature, copper has more affinity towards nickel which is on the coating side. Theoretical approach of the migration mechanism is the ability of the atoms in the lattice to overcome the bond of the neighbouring atoms to jump from one lattice site to another. $\mathrm{Cu}$ atoms must have had sufficient energy of vibration beyond the threshold frequency to overcome the activation energy to break the initial atomic and intermetallic bond and migrate under the influence of elevated temperature heat 
treatment. Another aspect is that, as the temperature is close to the melting temperature, the bonding of the element with the base metal $\mathrm{Al}$ is becoming weak that further facilitates and favours diffusion. The type of diffusion occurring in this case is similar to "chemical diffusion" coupled with thermal assistance. When two metals which are soluble in each other are in contact, migration occurs across the contacting interface. When solubility limit is reached after having diffused sufficient amount of one metal into the other, precipitation of a second phase occurs. This mechanism is much similar to the phenomenon of migration of chemically similar $\mathrm{Cu}$ into $\mathrm{Ni}$ side with the formation of a thick interface (boundary) that could be the result of precipitation beyond the solubility limit, of $\mathrm{Cu}$ in $\mathrm{Al}$. The diffusion constants for $\mathrm{Cu}$ in $\mathrm{Al}$ and $\mathrm{Cu}$ in $\mathrm{Ni}$ are $0.647 \mathrm{~cm}^{2} . \mathrm{s}^{-1}$ and $1.92 \mathrm{~cm}^{2} . \mathrm{s}^{-1}$ respectively [18]. The dependency of rate of diffusion with temperature is confirmed from the equation

$\mathrm{D}=\mathrm{D}_{0} \exp (-\mathrm{Q} / \mathrm{RT})$

where $\mathrm{D}_{0}$ is the constant, $\mathrm{Q}$ is the activation energy of diffusion process, $\mathrm{R}$ is the ideal gas constant and $\mathrm{T}$ is the absolute temperature. Thus the migrated $\mathrm{Cu}$ from the bulk aluminium alloy substrate could result in the precipitation with $\mathrm{Ni}$ from the coating as both the elements being similar chemically form a belt at the contact boundary (interface).

Zinc from the zincating film is absent and not detected at the proximity of the interface which could have been diffused beyond the detection limit as mentioned in the earlier section 3 .

Zinc whose melting point is $420{ }^{\circ} \mathrm{C}$ [19] had already been melted on heat treatment at $500{ }^{\circ} \mathrm{C}$ and diffused elsewhere possibly.

\subsection{Load variation at the interface}

Loads of 25 gf, 50 gf, 100 gf and 500 gf were applied using both Knoop and Vickers diamond tips at the interface of specimen 1 (Ni-P without zincating), specimen 2 (Ni-P with 
zincating) and specimen 3 (Ni-P/SiC composite coating). The present work chooses both Knoop and Vickers testing in order to apply varied pressure and stresses at the interface to identify the coating firmness. For instance, Knoop indent is shallower which is approximately $1 / 30$ of the long diagonal, whereas it is deeper for Vickers (the depth of the indent is $1 / 7$ of the average diagonal) [20]. For clarity in representation and for easy comparison, the indent marks were selectively chosen for $50 \mathrm{gf}$ and $500 \mathrm{gf}$ as shown in Figs. 5-9. As-deposited specimen 1 (Fig. 5) does not show any micro cracks around the indent mark. No visible detachment of the coating from the substrate is seen. Sharp edges of the mark towards coating side are the indication of higher hardness as compared to the not so well-defined border on substrate side. The plastic deformation is more prominent on the coating side whereas more of elasto-plastic nature is observed on the substrate side owing to the higher hardness for the former than the latter. On increasing the load, the sharpness is clearer on coating area but on the substrate side, the edges are irregular. Any sign of major coating peeling off from the substrate is not found. The substrate side appears dug muddy morphology. For as deposited specimen 2 (Fig. 6), no indication of any coating detachment is observed. Similar irregular edges were seen on substrate area and sharp edges towards the coating side. No significant micro cracks are seen at the vicinity of the corners on the coating. However, crack is seen on the substrate when indenting using Vickers at higher load of 500 gf. However, interface of the coating and the substrate which is in close proximity to the crack developed is not affected (no micro cracks along the interface or coating detachment) which indicates the firm bonding between the substrate and the coating. For composite coating (specimen 3) (Fig. 7), no major coating detachment is seen along the interface when indented with Knoop for both smaller and higher loads. Using Vickers tip, slight cracks are seen for higher load. However, smaller load does not cause any cracks. The crack developed could be due to slight imperfect nucleation during coating development owing to the disturbance by particles in the bath as 
compared to particles free coating development. Such observation is not seen at lower loads $(25,50$ and $100 \mathrm{gf})$.

Heat treated specimen 2 shows several micro cracks and the morphology looks dried and brittle (Fig. 8). Higher load of 500 gf using Knoop causes more micro cracks along the edge. The visibility of the cracks is clearer when indenting using Vickers tip with higher load of $500 \mathrm{gf}$. The micro cracks are observed along the interface initiating from the vertices of the diamond shape notch where stress is more concentrated. Also, several vertical cracks are seen towards the coating. No cracks are found at the vertices of the indent in the substrate region suggesting the low or negligible brittleness. Cracking along the interface alone, without any sign of cracking at the vertices falling on the substrate area is the indication of the weak adhesion at higher load post heat treatment. The interface is prone to cracking owing to the difference in rates of thermal expansion and contraction between the two dissimilar materials which could result in improper stacking of atoms at the contact region as compared to the asdeposited state.

For heat treated state for specimen 3 (Fig. 9), cracks are seen distinctly at 500 gf for both Knoop and Vickers. Higher load of Knoop indenting causes breakage of coating at the indenter apex. Interestingly, the crack initiating from the corner of the Vickers notch is stopped propagating further by the embedded particle. On the other hand, the crack developed at the other opposite corner continues in the matrix up to the interface. This indicates the role of particles in stopping the crack propagation. On observing both the region of the notch area on the substrate and the coating, the former shows more elastic deformation and the latter exhibits plastic deformation which is indicated by the clear borders and sharp corners as mentioned before. The area of the notch falling in substrate region appears dug muddy morphology having blurred and irregular boundary which might be due to elastic recovery. Lower loads of $25 \mathrm{gf}, 50 \mathrm{gf}$ and $100 \mathrm{gf}$ (not shown) do not affect much as compared 
to the higher one at $500 \mathrm{gf}$. However, Vickers indentation exhibits minor breakage at the interface as compared to Knoop indentation. The brittleness of the coating on heat treatment is also observed that affects the interfacial bonding owing to the dissimilar thermal expansion and contraction. Thus heat treatment results in the microcracks and plastic deformation at the interface especially when loading with high pressure using both the indents tips. However, as-deposited states exhibit the firmness of the coating irrespective of the zincating or without zincating without any microcracks as compared to the heat treated states. The elastic-plastic deformation is clear at the interface indicating the soft material nature of the Al substrate and the higher hardness behaviour of the electroless nickel coating.

\section{Conclusion remarks}

From the present investigation, some conclusions can be drawn pertaining to the insight of the interfacial changes on heat treatment and the loading responses upon particles inclusion in the coating

(1) Fine zinc crystallites (sub-micron sizes) were deposited as zincating layer.

(2) Absence of zinc at the vicinity of the interface on elevated temperature heat treatment could be due to diffusion of the element elsewhere making it too little to be detected by EDX or beyond the detection limit.

(3) Migration of $\mathrm{Cu}$ from the bulk alloy substrate to the contact interface results in the precipitation forming a well-defined belt along the interface. $\mathrm{Cu}$ being similar to $\mathrm{Ni}$ has affinity towards it in competition with $\mathrm{Al}$ from the base substrate.

(4) Zincating does not show much effect in terms of load varied indentation around the interface using both Knoop and Vickers indent tips.

(5) Heat treatment turns the Ni-P and Ni-P/SiC coatings more brittle with micro cracks observed along the interface especially at higher load (500 gf) owing to the 
dissimilarity in thermal expansion and contraction occurring at the interface. However, the propagation of micro crack is arrested by the second phase particles.

\section{Acknowledgements}

The funding from Queen's University Belfast as International studentship is gratefully acknowledged. Thanks to Dr. Mark Russell, Jim Knox and his team of our University for their help in SEM and sample preparation. Dr. R. Rajendran of B.S. Abdur Rahman University, Chennai is also gratefully appreciated.

\section{References}

[1] E.L. Rooy, Introduction to Aluminum and Aluminum Alloys, Properties and Selection: Nonferrous Alloys and Special-Purpose Materials, Vol 2, ASM Handbook, ASM International, 1990, pp 3-14.

[2] K.G. Keong, W. Sha, S. Malinov, Hardness evolution of electroless nickel-phosphorus deposits with thermal processing, Surf. Coat. Technol. 168 (2003) 263-274.

[3] M. Franco, W. Sha, S. Malinov, R. Rajendran, Phase composition, microstructure and microhardness of electroless nickel composite coating co-deposited with $\mathrm{SiC}$ on cast aluminium LM24 alloy substrate, Surf. Coat. Technol. 235 (2013) 755-763.

[4] M. Franco, W. Sha, S. Malinov, H. Liu, Micro-scale wear characteristics of electroless Ni-P/SiC composite coating under two different sliding conditions, Wear 317 (2014) 254264.

[5] R.A. Shakoor, R. Kahraman, U. Waware, Y. Wang, W. Gao, Properties of electrodeposited Ni-B-Al $\mathrm{O}_{3}$ composite coatings, Mater. Des. 64 (2014) 127-135. 
[6] R.A. Shakoor, R. Kahraman, U.S. Waware, Y. Wang, W. Gao, Synthesis and properties of electrodeposited Ni-B-CeO 2 composite coatings, Mater. Des. 59 (2014) 421-429.

[7] F.S. Pettit, Surface Engineering of Aluminum and Aluminum Alloys, Surface Engineering, Vol 5, ASM Handbook, ASM International, 1994, pp 784-804.

[8] K. Murakami, M. Hino, M. Hiramatsu, K. Osamura, T. Kanadani, Effect of zincate treatment on adhesion of electroless nickel-phosphorus coating for commercial pure aluminum, Mater. Trans. 47 (2006) 2518-2523.

[9] G. Qi, L.G.J. Fokkink, K.H. Chew, Zincating morphology of aluminum bond pad: its influence on quality of electroless nickel bumping, Thin Solid Films 406 (2002) 219-223.

[10] G. Qi, X. Chen, Z. Shao, Influence of bath chemistry on zincate morphology on aluminum bond pad, Thin Solid Films 406 (2002) 204-209.

[11] Jeong-Gi Jin, Sung-Ki Lee, Young-Ho Kim, Adhesion improvement of electroless plated Ni layer by ultrasonic agitation during zincating process, Thin Solid Films 466 (2004) 272278.

[12] E. Valova, J. Dille, S. Armyanov, J. Georgieva, D. Tatchev, M. Marinov, J.-L. Delplancke, O. Steenhaut, A. Hubin, Interface between electroless amorphous Ni-Cu-P coatings and Al substrate, Surf. Coat. Technol. 190 (2005) 336-344.

[13] S. Egoshia, K. Azumia, H. Konnoa, K. Ebiharab, Y. Taguchi, Effects of minor elements in Al alloy on zincate pretreatment, Appl. Surf. Sci. 261 (2012) 567-573.

[14] J. Sudagar, J. Lian, W. Sha, Electroless nickel, alloy, composite and nano coatings - A critical review, J. Alloy. Compd. 571 (2013) 183-204. 
[15] A.L. Kearney, Properties of Cast Aluminum Alloys, Properties and Selection:

Nonferrous Alloys and Special-Purpose Materials, Vol 2, ASM Handbook, ASM International, 1990, pp 152-177.

[16] Al (Aluminum) Binary Alloy Phase Diagrams, Alloy Phase Diagrams, Vol 3, ASM Handbook, ASM International, 1992, pp 2.4-2.56.

[17] Cu (Copper) Binary Alloy Phase Diagrams, Alloy Phase Diagrams, Vol 3, ASM Handbook, ASM International, 1992, pp 2.167-2.182.

[18] C.R. Brooks, Principles of Heat Treating of Nonferrous Alloys, Heat Treating, Vol 4, ASM Handbook, ASM International, 1991, pp 823-840.

[19] Properties of Pure Metals, Properties and Selection: Nonferrous Alloys and SpecialPurpose Materials, Vol 2, ASM Handbook, ASM International, 1990, pp 1099-1201.

[20] G.F. Vander Voort, Microindentation Hardness Testing, Mechanical Testing and Evaluation, Vol 8, ASM Handbook, ASM International, 2000, pp 221-231. 
Table 1. Pre-treatment processes of aluminium substrate prior to plating [3]

\begin{tabular}{lllll}
\hline Process & Chemicals & Temperature & Time & $\begin{array}{l}\text { Degree of } \\
\text { agitation }\end{array}$ \\
\hline Degreasing & $\mathrm{C}_{6} \mathrm{H} 6 \mathrm{O}$ (acetone) & Room & $3-5 \mathrm{~min}$. & None \\
$\begin{array}{l}\text { Alkaline } \\
\text { cleaning }\end{array}$ & $\begin{array}{l}5.75 \mathrm{~g} / 1 \mathrm{Na}_{3} \mathrm{PO}_{4}, \\
5.75 \mathrm{~g} / \mathrm{Na}_{2} \mathrm{SiO}_{3}\end{array}$ & $60-65^{\circ} \mathrm{C}$ & $\sim 3 \mathrm{~min}$. & Mild \\
Acid neutralising & $\begin{array}{l}13 \% \mathrm{vol} . \mathrm{HNO}_{3} \text { (initial conc. } \\
\geq 65 \%)\end{array}$ & Room & $\sim 20 \mathrm{sec}$. & Mild \\
Zincating & $100 \mathrm{~g} / 1 \mathrm{ZnO}, 525 \mathrm{~g} / 1 \mathrm{NaOH}$ & Room & $\sim 20 \mathrm{sec}$ & Mild \\
\hline
\end{tabular}


Table 2. Plating process condition [3]

\begin{tabular}{ll}
\hline Parameter & Value \\
\hline $\mathrm{pH}$ & $4.8-4.9$ \\
Temperature & $88 \pm 2{ }^{\circ} \mathrm{C}$ \\
Time & $80 \mathrm{~min}$. \\
SiC concentration & $2 \mathrm{~g} / \mathrm{l}$ \\
Agitation & Magnetic stirrer along with sample rotator \\
\hline
\end{tabular}


Table 3. Chemical compositions of the coatings in wt. \% from EDX spectra

\begin{tabular}{|c|c|c|c|c|c|c|c|c|c|}
\hline Sample & Fig. & Spectrum & $\mathbf{N i}$ & $\mathbf{P}$ & Zn & Al & Si & $\mathbf{C u}$ & Others* \\
\hline Flat Zn & 1 & Box & - & - & $15.9 \pm 0.3$ & $73.7 \pm 0.4$ & $2.0 \pm 0.1$ & $2.5 \pm 0.2$ & $2.8 \mathrm{Fe}, 2.7 \mathrm{O}, 0.4 \mathrm{Mn}$ \\
\hline \multirow[t]{3}{*}{ Specimen 2 (as-deposited) } & 2 & S16 & $91.6 \pm 0.4$ & $8.4 \pm 0.4$ & - & - & - & - & - \\
\hline & & S13 & $7.0 \pm 0.3$ & $0.9 \pm 0.1$ & $1.8 \pm 0.2$ & $57.8 \pm 0.4$ & $28.4 \pm 0.3$ & $1.3 \pm 0.2$ & $2.3 \mathrm{Fe}, 0.6 \mathrm{Mn}$ \\
\hline & & S18 & $0.9 \pm 0.2$ & - & - & $14.6 \pm 0.2$ & $82.5 \pm 0.3$ & $0.7 \pm 0.2$ & $1.3 \mathrm{Fe}$ \\
\hline \multirow{2}{*}{ Specimen 3 (as-deposited) } & & Interface & $11.8 \pm 0.4$ & $0.9 \pm 0.1$ & $1.2 \pm 0.3$ & $69.6 \pm 0.6$ & $6.7 \pm 0.2$ & $2.1 \pm 0.3$ & 7.80 \\
\hline & & Substrate ${ }^{\#}$ & $1.3 \pm 0.1$ & - & $1.0 \pm 0.2$ & $81.4 \pm 0.4$ & $6.5 \pm 0.1$ & $3.2 \pm 0.2$ & 6.60 \\
\hline \multirow[t]{2}{*}{ Specimen $3\left(300^{\circ} \mathrm{C}\right)$} & & Coating $^{\#}$ & $94.5 \pm 0.3$ & $5.5 \pm 0.3$ & - & - & - & - & - \\
\hline & & Interface & $31.0 \pm 1.9$ & $1.1 \pm 0.1$ & $2.6 \pm 0.3$ & $63.1 \pm 1.7$ & $1.0 \pm 0.1$ & - & $1.2 \mathrm{O}$ \\
\hline \multirow{3}{*}{ Specimen $3\left(400^{\circ} \mathrm{C}\right)$} & & S6 & - & - & $1.6 \pm 0.2$ & $87.7 \pm 0.4$ & $4.9 \pm 0.2$ & $2.1 \pm 0.3$ & 3.60 \\
\hline & & S7 & - & - & - & $53.8 \pm 1.1$ & $18.9 \pm 0.5$ & - & $21.9 \mathrm{Fe}, 5.5 \mathrm{O}$ \\
\hline & & S8 & $23.3 \pm 1.8$ & $1.8 \pm 0.1$ & - & $42.1 \pm 1.0$ & $21.6 \pm 0.6$ & $3.7 \pm 0.4$ & 7.50 \\
\hline Specimen $2\left(500^{\circ} \mathrm{C}\right)$ & 4 & S6 & $33.8 \pm 1.5$ & - & - & $36.4 \pm 0.9$ & $0.9 \pm 0.1$ & $25.8 \pm 0.8$ & $1.2 \mathrm{Mg}, 1.8 \mathrm{O}$ \\
\hline
\end{tabular}

* $\mathrm{O}$ (oxidation)

\# Approximate distance to the interface is $6 \mu \mathrm{m}$ 


\section{List of figure captions}

Fig. 1. Micrographs of (a) bare aluminium before zincating and (b) Zincating morphology. EDX for zinc confirmation onto flat aluminium substrate from the boxed area is given in Table 3

Fig. 2. Cross section of as-deposited specimen 2 (Ni-P with zincating)

Fig. 3. Cross section of specimen $3\left(\mathrm{Ni}-\mathrm{P} / \mathrm{SiC}\right.$ with zincating) heat treated at $400{ }^{\circ} \mathrm{C}$

Fig. 4. Cross section of specimen 2 (Ni-P with zincating) heat treated at $500{ }^{\circ} \mathrm{C}$

Fig. 5. Micrographs of indent marks showing non-damage coating at loads of $500 \mathrm{gf}$ for specimen 1 (as-deposited)

Fig. 6. Micrograph of indent mark showing non-detachment at load of $500 \mathrm{gf}$ for specimen 2 (as-deposited)

Fig. 7. Micrographs of indent marks showing stability of coating at loads of $50 \mathrm{gf}$ and $500 \mathrm{gf}$ for specimen 3 (as-deposited)

Fig. 8. Micrographs showing micro cracks and coating detachment on indentation at load of $500 \mathrm{gf}$ for specimen 2 (heat treated at $400{ }^{\circ} \mathrm{C}$ )

Fig. 9. Micrographs showing micro crack being ceased by reinforced particles for specimen 3 (heat treated at $400{ }^{\circ} \mathrm{C}$ ) 

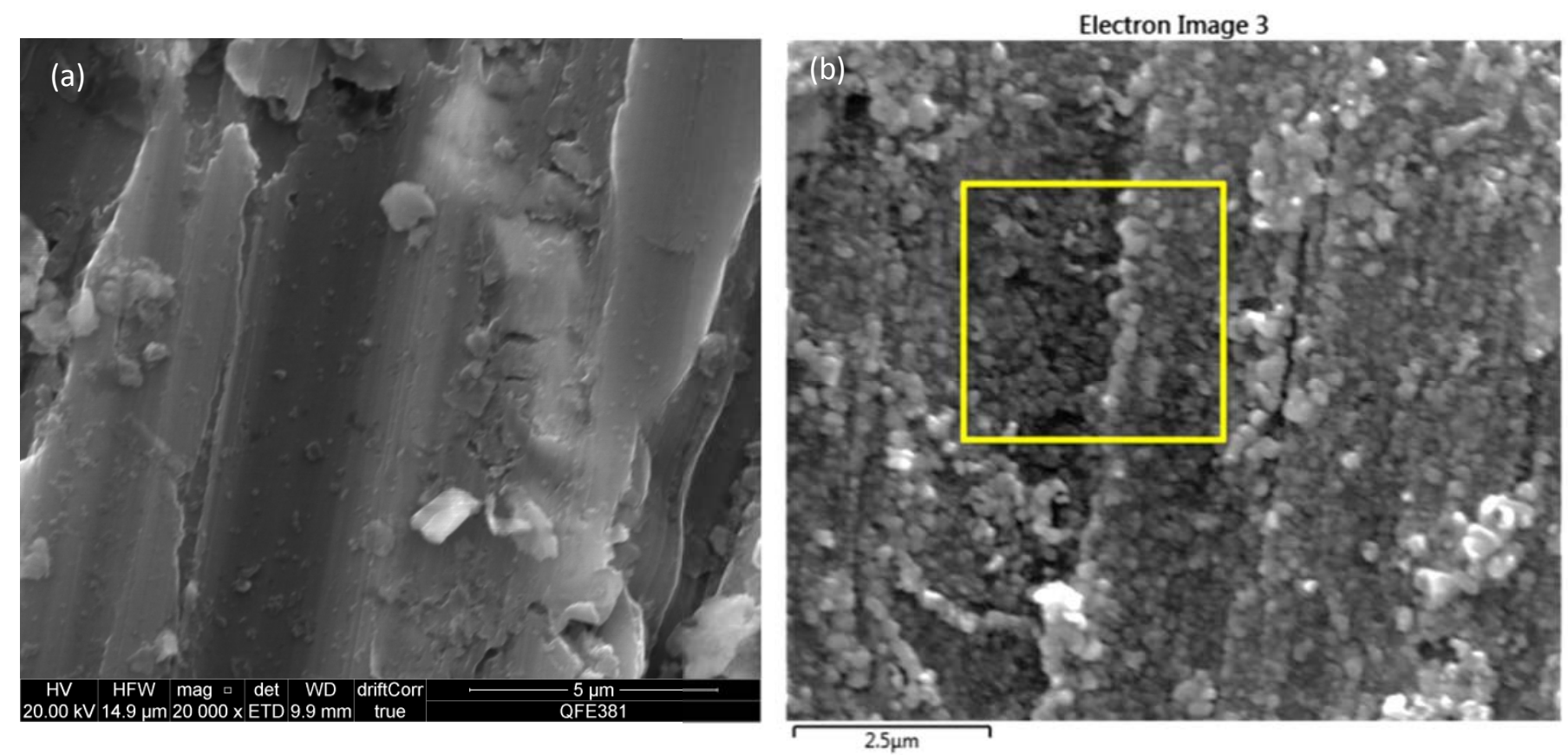

Fig. 1 
Electron Image 11

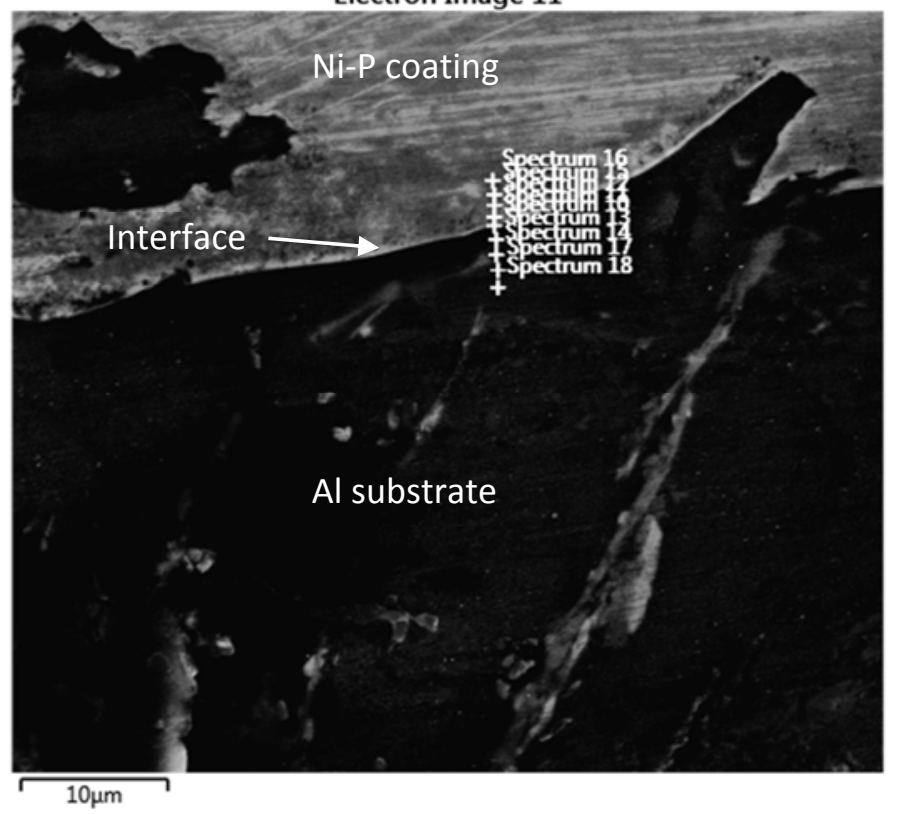

Fig. 2 
Electron Image 1

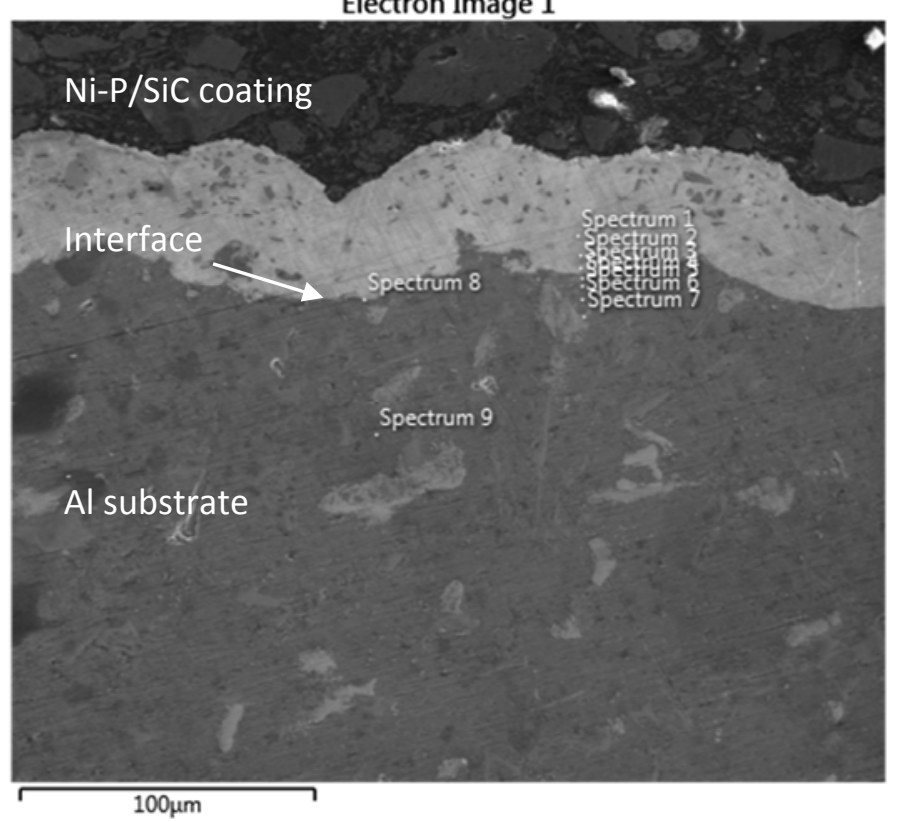

Fig. 3 
Electron Image 3

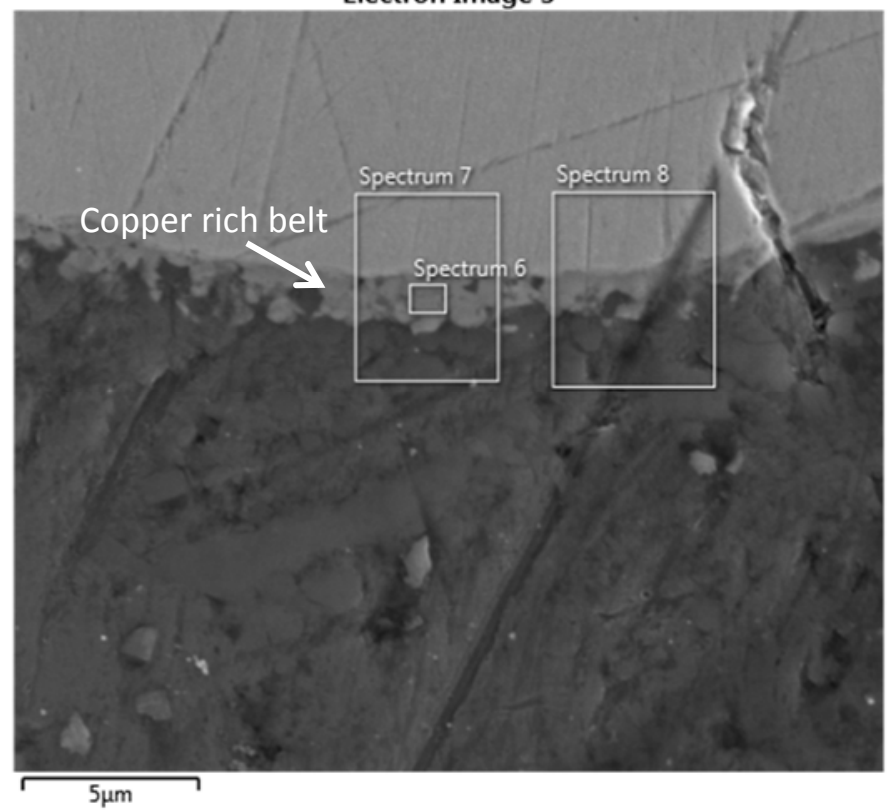

Fig. 4 

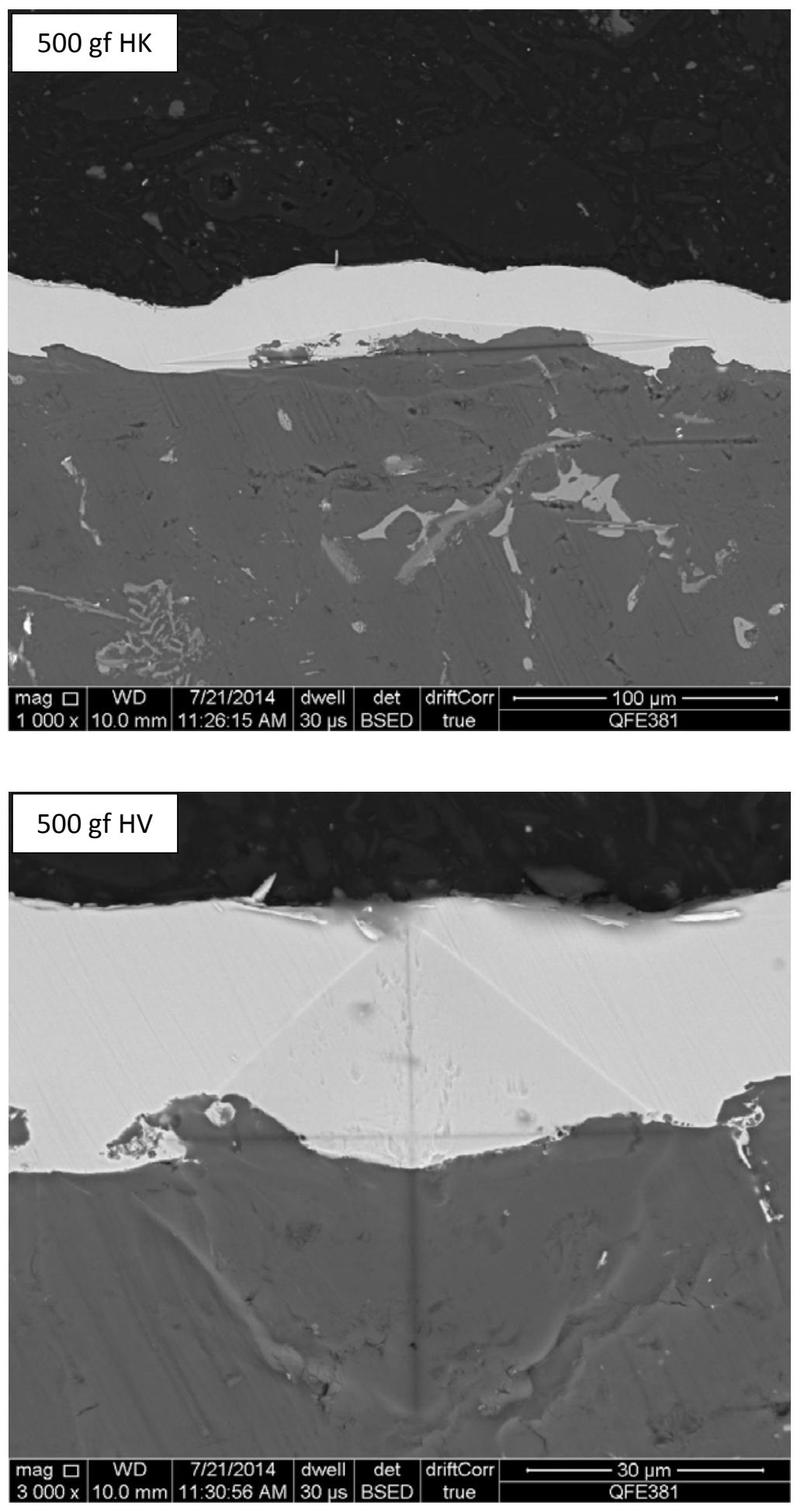

Fig. 5 


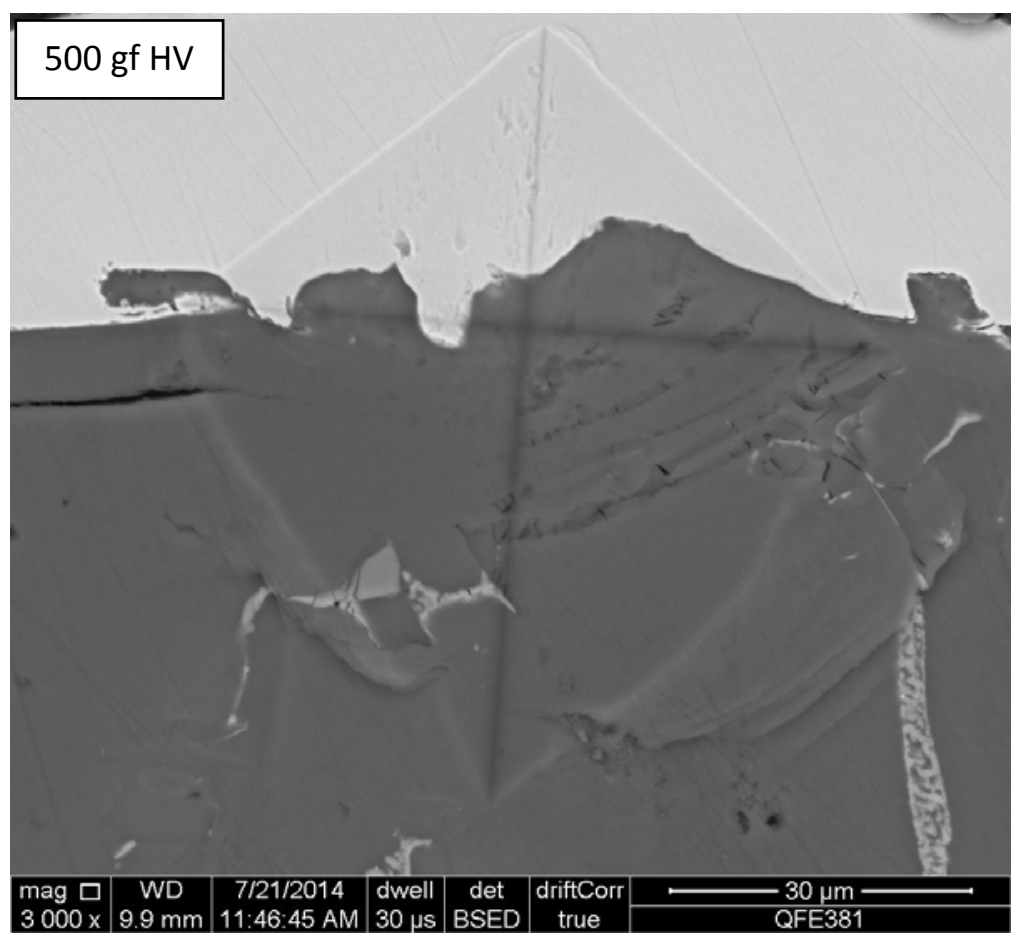

Fig. 6 


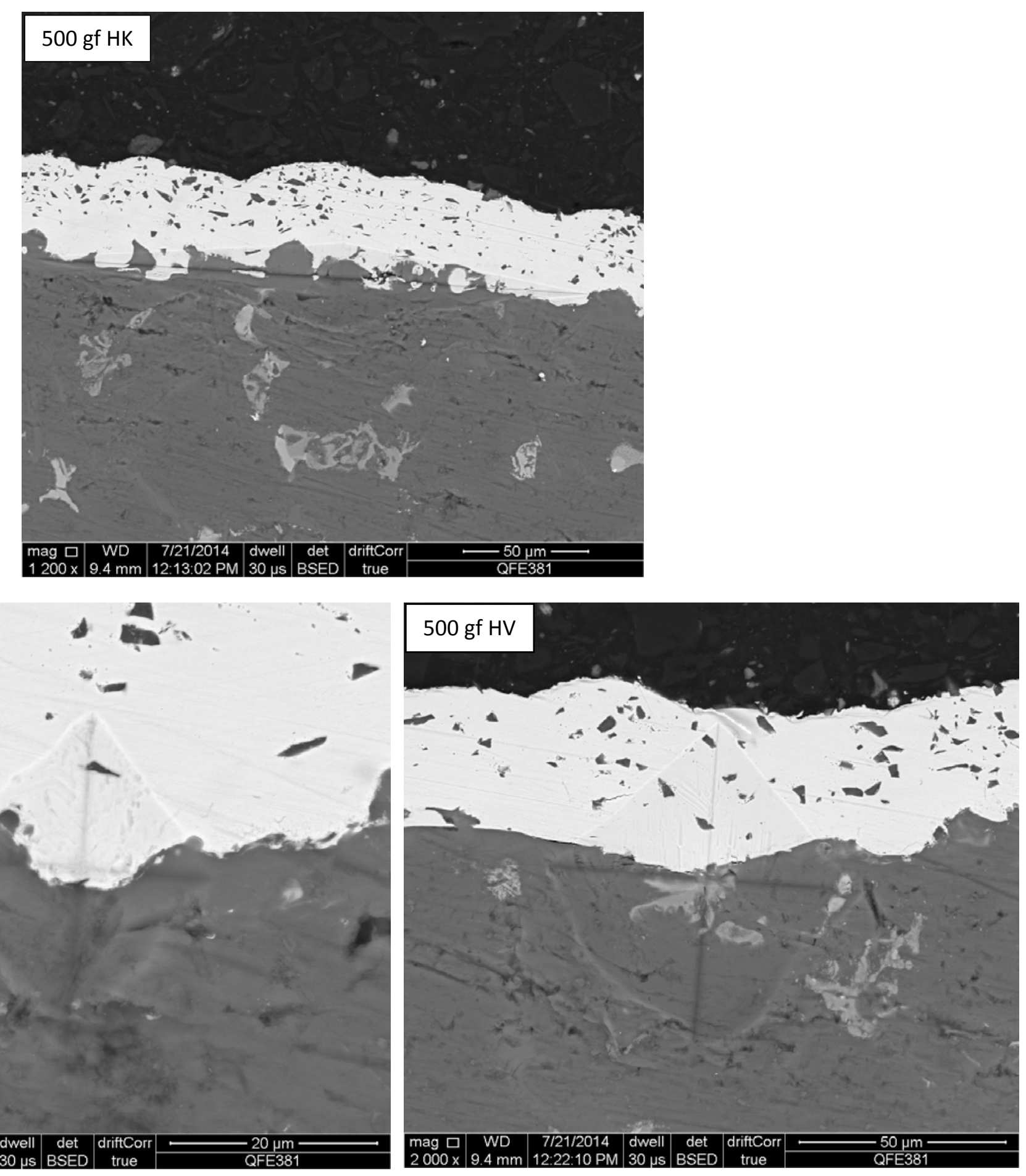

Fig. 7 

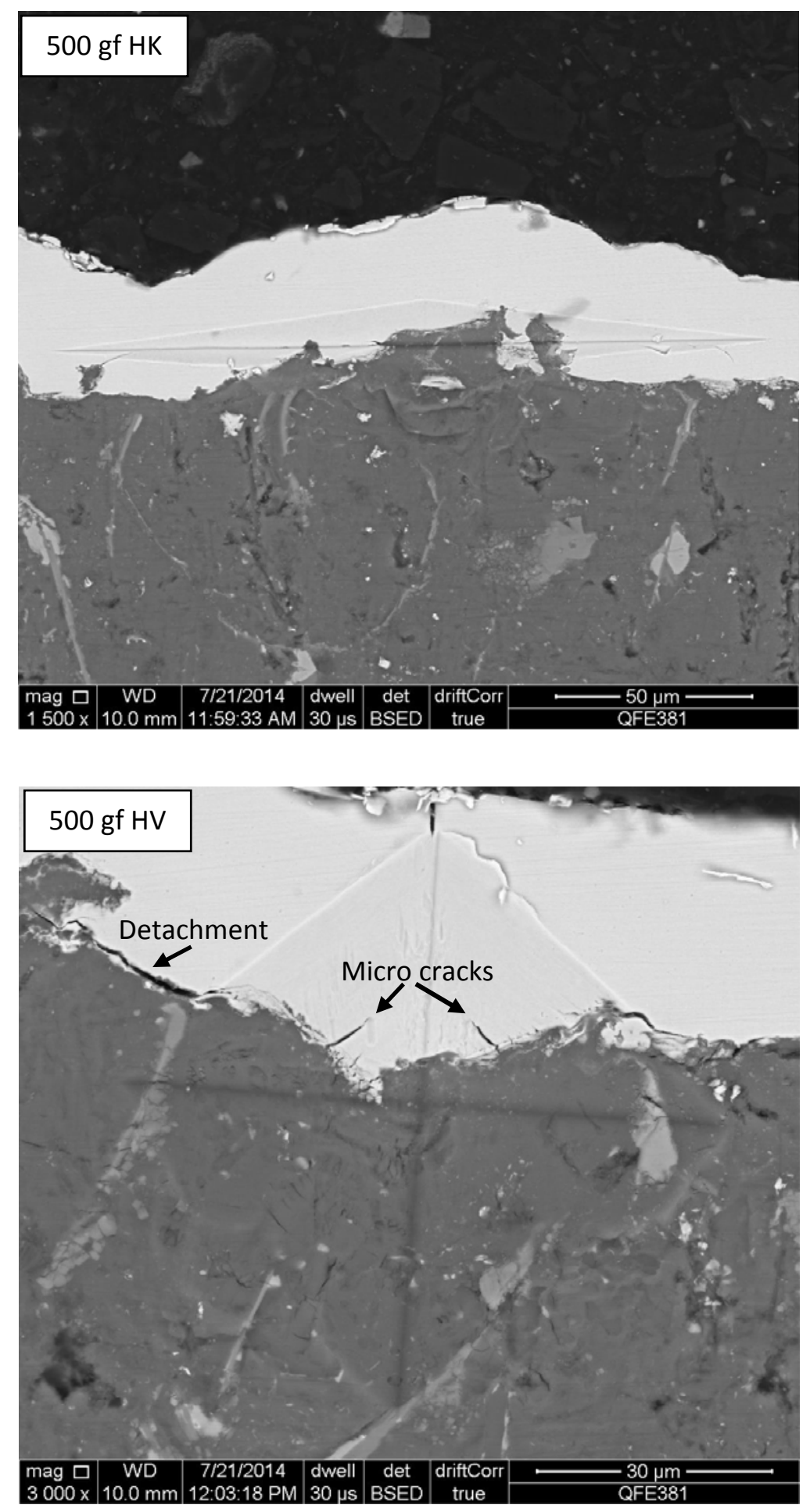

Fig. 8 

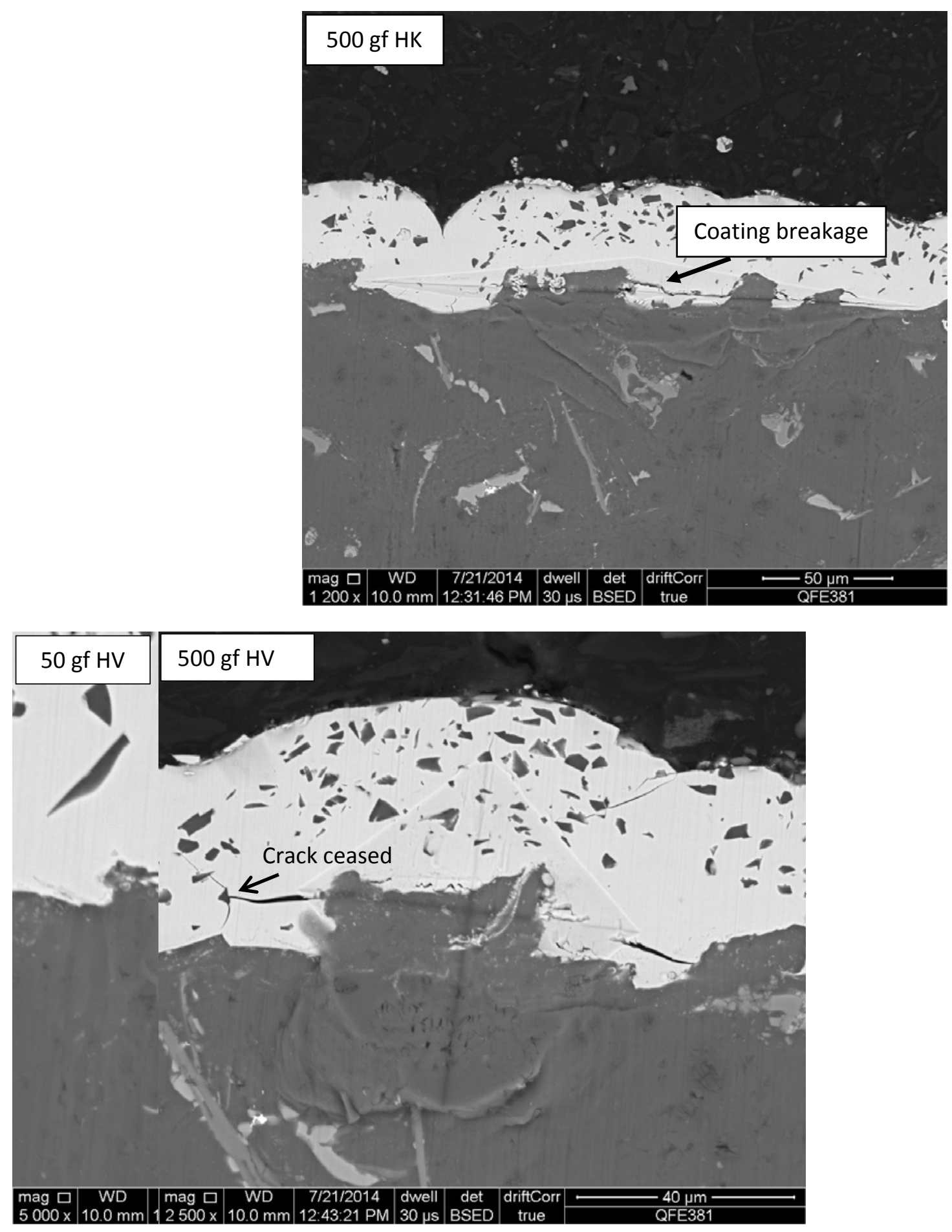

Fig. 9 